\title{
Biological and Structural Characterization of Y-TZP for Implant Abutments
}

Ana Flávia Sanches Borges ${ }^{1 *}$, Ana Carolina Morandini² ${ }^{2}$ Carla Müller Ramos ${ }^{3}$, Marianne Barbosa Salgado de Oliveira ${ }^{4}$, AmericoTabata $^{5}$ and Carlos Ferreira Santos ${ }^{6}$

${ }^{1}$ Department of Operative Dentistry, Endodontics and Dental Materials, Bauru School of Dentistry, University of São Paulo (FOB/USP), Brazil ${ }^{2}$ Doctoral Student of Periodontology, Department of Biological Sciences, Bauru School of Dentistry, University of São Paulo (FOB/USP), Brazil ${ }^{3}$ Doctoral Student of Operative Dentistry at Bauru School of Dentistry, University of São Paulo, (FOB/USP), Brazil

${ }^{4}$ Student of Dentistry at Bauru School of Dentistry, University of São Paulo, (FOB/USP), Brazil

${ }^{5}$ Institute of Physics of Bauru. State University of São Paulo (FOB/USP), Brazil

${ }^{6}$ Department of Biological Sciences, Bauru School of Dentistry, University of São Paulo (FOB/USP), Brazil

\begin{abstract}
The aim of this study was to performed to characterize three different cold isostatic pressed Y-TZP, one being controlled manufacturing, concerning its biocompatibility in contact with cultured human gingival fibroblasts and its crystalline structure by Micro-Raman Spectroscopy.
\end{abstract}

Keywords: Implant abutments; Y-TZP; Fibroblasts

\section{Introduction}

The development of high-strength ceramics such as Yttrium Tetragonal Zirconia Polycrystal (Y-TZP) for application in dental implants reconstructions including abutments and crows has emerged as a viable alternative by your biological and mechanical properties beyond better esthetic results [1]. It is a material that shows improvements in its properties until reaching a stability of the tetragonal phase at room temperature [2]. The Y-TZP chemistry stability ensures its biocompatibility and contributes to its optimal aesthetic and mechanical properties $[3,4]$. Know the biocompatibility and intrinsic structures of Y-TZPs can predict the clinical success of rehabilitation.

In cases in which the Y-TZP is used as abutments, the contacts with the gingival tissue occurs [5,6]. Fibroblasts are the most numerous resident cells in periodontium. However, they are needed for any implant or abutment materials that are not toxic and to be inert to them $[7,8]$. The formation of the epithelial attachment is influenced by the material composition of the transgingival implant components [810]. A previous study showed that Ti surfaces may play an important role in modulating the cytokine release in cultured Human Gingival Fibroblasts (HGF) [11]. In addition, studies have shown that zirconia

\begin{tabular}{|c|c|c|c|}
\hline GROUPS & $\begin{array}{c}\text { MATERIAL } \\
\text { MANUFACTURER }\end{array}$ & CON & OSITION \\
\hline \multirow{7}{*}{ EP } & \multirow{7}{*}{ Experimental } & $\mathrm{Zr}(\mathrm{hf}) \mathrm{O}_{2}=94.7 \%$ & $\begin{array}{c}\text { Zirconium Dioxide + } \\
\text { Hafium }\end{array}$ \\
\hline & & $\mathrm{Y}_{2} \mathrm{O}_{3}=5.25 \%$ & Itrium Trioxide \\
\hline & & $\mathrm{SiO}_{2}=0.020 \%$ & Silicon Dioxide \\
\hline & & $\mathrm{Fe}_{2} \mathrm{O}_{3}=0.010 \%$ & Ferrum Trioxide \\
\hline & & $\mathrm{Na}_{2} \mathrm{O}=0.010 \%$ & Sodium Oxide \\
\hline & & $C L=0.020 \%$ & Clorium \\
\hline & & $\mathrm{TiO}_{2}=0.010 \%$ & Titanium Dioxide \\
\hline \multirow{5}{*}{ ST } & \multirow{5}{*}{$\begin{array}{c}\text { Schuetz - Schuetz } \\
\text { (Germany) }\end{array}$} & $\mathrm{Zr}\left(\mathrm{O}_{2}\right)=<96 \%$ & Zirconium Dioxide \\
\hline & & $\mathrm{HfO}_{2}=>1 \%$ & Hafium Dioxide \\
\hline & & $\mathrm{Y}_{2} \mathrm{O}_{3}=>4 \%$ & Yttrium Trioxide \\
\hline & & $\mathrm{Al}_{2} \mathrm{O}_{3}=<1 \%$ & Aluminium Trioxide \\
\hline & & $\mathrm{SiO}=<0.02 \%$ & Silicon Oxide \\
\hline \multirow{6}{*}{ ZK } & \multirow{6}{*}{$\begin{array}{c}\text { Zirkonzahn - } \\
\text { Zirkonzahn } \\
\text { (Germany) }\end{array}$} & $\mathrm{ZrO}_{2}=91.5 \%$ & Zirconium Dioxide \\
\hline & & $\mathrm{HfO}_{2}=>3.0 \%$ & Hafium Dioxide \\
\hline & & $\mathrm{Y}_{2} \mathrm{O}_{3}=5 \%$ & Itrium Trioxide \\
\hline & & $\mathrm{SiO}_{2}=0.020 \%$ & Silicon Dioxide \\
\hline & & $\mathrm{Fe}_{2} \mathrm{O}_{3}=0.0050 \%$ & Ferrum Trioxide \\
\hline & & $\mathrm{Na}_{2} \mathrm{O}=0.01 \%$ & Sodium Oxide \\
\hline
\end{tabular}

Table 1: Groups' names, materials, manufacturers and detailed compositions of the three Y-TZP discs studied. *Compositions according to the Manufacturer and Chemical Engineer information. bacterial adhesion, inflammatory infiltrate, micro vessel densities and vascular endothelial growth factor expressions are low compared to titanium, a material also used for abutments. This suggests that zirconia maintains a healthy periodontal tissue $[12,13]$.

A highly localized stress on the zirconia surface results in a phase transformation from tetragonal into monoclinic or cubic forms [14,15]. The cracks dissipation is limited by this crystalline forms change, decreasing the risk of ions release from the bulk of the material. For periodontal tissue, the higher the strength of the material, the lesser damages can occur [16].

\section{Materials and Methods}

\section{Y-TZP Blocks (Manufacturing controlled)}

The blocks were obtained from isostatic pressing. This process consists of applying pressure in all directions during the pressing. It was used a flexible elastomeric membrane as a matrix. The elastomeric matrix cavity was filled by EP composition and sealed over with a metal plate (Table 1). The matrix outer surfaces were pressed by a fluid that transmits the pressures toward the matrix resulting in the powder compaction (Figure 1). The pressure was $120 \mathrm{MPa}$, for 5 seconds of each block at the temperature of $25^{\circ} \mathrm{C}$ of and the humidity of $60 \%$.

\section{Y-TZP discs}

The Y-TZP discs EP, ST, ZK used in this study were machined from pre-sinterized zirconia blocks. The discs were prepared with a 14.4 $\mathrm{mm}$ diameter and $3.4 \mathrm{~mm}$ thickness before the final sintering. During the final sintering, the zirconia discs shrink approximately $20 \%$. The final zirconia disks dimensions were $12 \mathrm{~mm}$ in diameter and $2.7 \mathrm{~mm}$ in thickness. Ten discs from each group were fabricated and tested (Table 1).

\section{Cell culture}

HGFs were primarily cultured as previously described $[17,18]$.

*Corresponding author: Ana Flávia Sanches Borges, Department of Operative Dentistry, Endodontics and Dental Materials, Bauru School of Dentistry, University of São Paulo (FOB/USP), Brazil, Tel: +55-14-3235-8267; E-mail: afborges@fob.usp.br

Received October 28, 2013; Accepted December 14, 2013; Published December 16, 2013

Citation: Borges AFS, Morandini AC, Ramos CM, de Oliveira MBS, Tabata A, et al. (2013) Biological and Structural Characterization of Y-Tzp for Implant Abutments. J Tissue Sci Eng 5: 132. doi:10.4172/2157-7552.1000132

Copyright: (c) 2013 Borges AFS, et al. This is an open-access article distributed under the terms of the Creative Commons Attribution License, which permits unrestricted use, distribution, and reproduction in any medium, provided the original author and source are credited. 


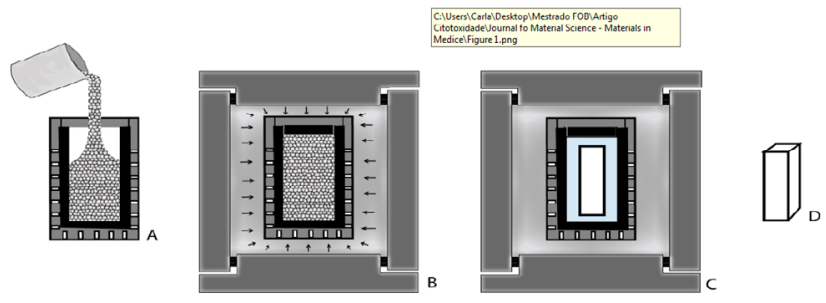

Figure 1: Sequence of Y-TZP EP Blocks Compression. A. The powder was put into the elastomeric matrix. B,C. The pressure was transferred towards the matrix resulting into a block. $D$. The block ready for use.

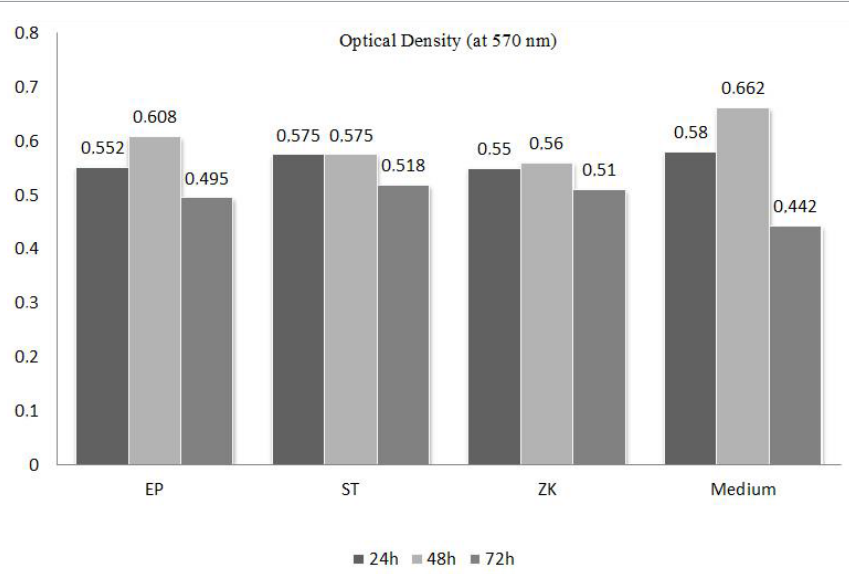

Figure 2: Direct Cytotoxic Evaluation of EP, ST (Shuetz), ZK (Zirkonzhan) $Y-T Z P$ discs and the Medium (control group). The data is expressed as the mean values at 24,48 and 72 hours. No differences were shown for all Y-TZP discs and the control group.

Briefly, the fibroblasts were obtained from the gingival explants of clinically non-inflamed tissue, retrieved from the gingival margin of three volunteer donors after informed written consent in accordance with the Institutional Review Board of the Bauru School of Dentistry, University of São Paulo. The cells were grown in Dulbecco's Modified Eagle's Medium (DMEM; Invitrogen Life Technologies, Carlsbad, CA) supplemented with $10 \%$ fetal bovine serum (Invitrogen Life Technologies, Carlsbad, CA), and antibiotics $(600 \mu \mathrm{L} / \mathrm{mL}$ penicillin, $300 \mu \mathrm{L} / \mathrm{mL}$ gentamicin sulfate, and $100 \mu \mathrm{L} / \mathrm{mL}$ amphotericin B), incubated at $37^{\circ} \mathrm{C}$ in a humidified atmosphere of $5 \%$ carbon dioxide until confluence and were used between the fourth and eighth passages for the experiments [17].

\section{Cell viability assay}

The cell viability was examined with 3-(4.5-dimethylthiazol2-yl)-2,5-diphenyltetrazolium bromide (MTT) assay (Sigma Aldrich, St Louis, MO, USA).This test is based on the formation of a colored product (formazan) through the mitochondrial succinate dehydrogenase metabolism in cells. The test allows for the evaluation of viable, metabolic active cells. Briefly, the cells (in a density of $2 \times$ $10^{4}$ ) were incubated in 24-well plates on zirconia discs for 24, 48 or $72 \mathrm{hrs}$ (Directcytotoxic Evaluation-DCE). Concurrently, the cells were incubated with a medium that was previously in contact with the zirconia discs for 24, 48 or $72 \mathrm{hrs}$ (Indirect Cytotoxic Evaluation - ICE). After discarding the supernatants, the adherent cells were treated with $5 \mathrm{mg} / \mathrm{mL}$ of tetrazolium salt (MTT; Sigma-Aldrich, St. Louis, MO) in a phosphate buffer and added with the DMEM medium. After incubation at $37^{\circ} \mathrm{C}$ for $4 \mathrm{hrs}$, the medium was discarded and Dimethyl sulfoxide (DMSO) was added to solubilize the formazan produced. Afterward, the plates were centrifuged $(200 \mathrm{~g}, 7 \mathrm{~min})$. The absorbance of the formazan present in the supernatant was measured at a wavelength of $570 \mathrm{~nm}$ (Fluostar Optima, BMG Lab tech, Ortenberg, Germany). The mean absorbance values were corrected for a blank (medium only) and the results were reported as optical density.

\section{Micro Raman Spectroscopy}

Two discs from each group were evaluated. The Micro-Raman measurements were carried out at room temperature in backscattering geometry by means of a Jobin Yvon Micro Raman system, model T64000 (Groupe Horiba- Longjumeau/France) at the Physics Institute of São Paulo State University (UNESP, Bauru, SP, Brazil). The 514.5 $\mathrm{nm}(2.41 \mathrm{eV})$ radiation of an argon ion laser (Spectra Physic, Inc., California/USA) was used for the excitation. The beam was focused by means of a microscope of 500x magnification, the laser spot had a diameter of about $5 \mu \mathrm{m}$. No polarization analyzer was used for the scattered beam. In order to avoid any thermal damage, the laser power was kept as low as $10 \mathrm{~mW}$. The Raman spectra was analyzed by means of a double subtractive monochromator, with a focal length of $0.64 \mathrm{~m}$ and equipped with a diffraction grating with 1800 grooves $/ \mathrm{mm}$. The slit width was set to $200 \mu \mathrm{m}$ which provided us with a spectral resolution of about $2 \mathrm{~cm}^{-1}$. The 5 spectra from each zirconia discs were recorded with a CCD (Spectra One -Group Horiba - Longjumeau/France) camera.

\section{Statistical analysis}

The cellular viability data was analyzed by the two-way analysis of variance test followed by the Tukey post-test. Values of $\mathrm{p}<0.05$ were considered statistically significant.

The 5 spectra within each group had exactly the same spectral patterns and a mean was obtained from each group. The spectra among the groups were compared with regards to the differences among the wave numbers and the broadening bands.

\section{Results}

\section{Cell viability}

The optical densities of the formazan produced by the HGF in the EP, ST and ZK discs groups were measured after 24,48 or $72 \mathrm{hrs}$ via the MTT assay. For the Direct Cytotoxic Evaluation (DCE), no significant difference ( $p>0.05)$ was detected between the EP, ST and ZK zirconia discs regarding the cell proliferation, regardless of the time evaluated (Figure 2). Similarly, no significant difference $(\mathrm{p}>0.05)$ was observed between the EP, ST and ZK zirconia discs regarding the cell viability at $24 \mathrm{hrs}$ for the Indirect Cytotoxic Evaluation (ICE). Conversely, a significant increase in the cellular viability was observed for the EP and ST discs at $72 \mathrm{hrs}$ when compared to $48 \mathrm{hrs}(\mathrm{p}<0.05)$ (Figure 3).

\section{Micro Raman Spectroscopy}

The peaks used in this study corresponded to the main bands related to the zirconia component [14]. Strong peaks were found at 260 , 320,464 and $642 \mathrm{~cm}^{-1}$. Additional weak features were observed for all groups at $147 \mathrm{~cm}^{-1}$. Those spectra features were very similar among the groups with no visible broadening of any band. However, a broadening band was observed only for the ZK at $403 \mathrm{~cm}^{-1}$. The spectra of each group were composed of 924 data points in a spectral region between $\sim 100$ and $700 \mathrm{~cm}^{-1}$. The mean spectra of the groups have the same baseline; however, they were dissociated to improve the visualization of each spectrum (Figure 4). 


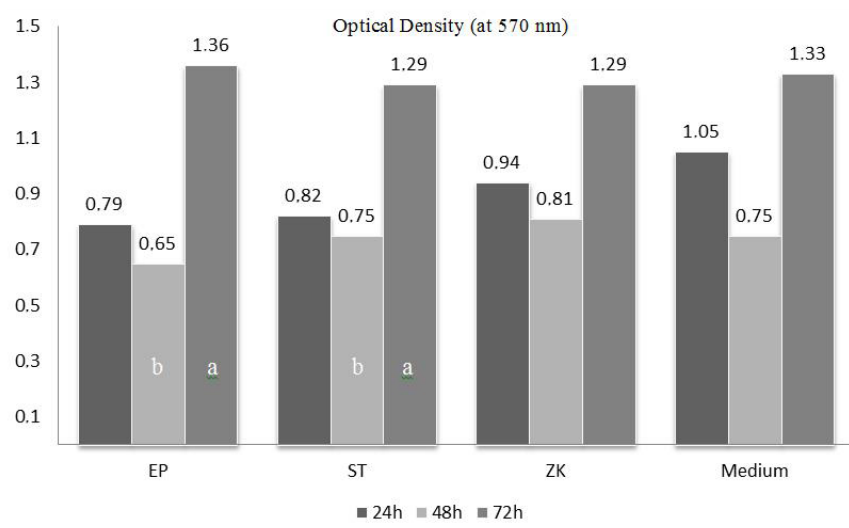

Figure 3: Indirect Cytotoxic Evaluation of EP, ST (Shuetz), ZK (Zirkonzhan) $Y$-TZP extracts and the Medium (control group). The data is expressed as the mean values at 24,48 and 72 hours. A difference was shown between the cell viability at 72 hrs (letter a) compared to 48 hrs (letter b) for the EP and ST.

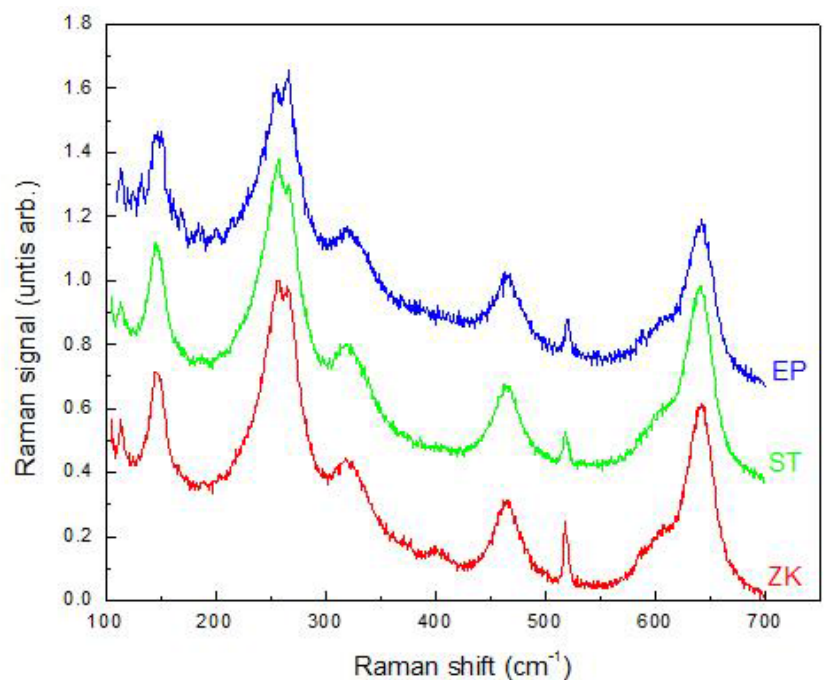

Figure 4: Raman spectra of the EP, ST and ZK groups. The peaks identified are related to Yttria tetragonal Y-TZP polycrystalline structures ( $\sim 260,320$, 464 , and $\left.147 \mathrm{~cm}^{-1}\right)$.

\section{Discussion}

The great advantage of controlling the production of blocks of Y-TZP is able to dominate the processing method used and the source and amount of raw material used. EP were designed to obtain a material with controlled composition by cold isostatic pressing and pre-sintering in order to obtain a Y-TZP inert abutments since it is need to be nontoxic in order to help the attachment and growth of the surrounding gingiva [8]. The composition of EP differs from the others by the presence of titanium oxide $\left(\mathrm{TiO}_{2}\right)$, chlorine $(\mathrm{Cl})$, iron oxide $\left(\mathrm{Fe}_{2} \mathrm{O}_{3}\right)$ and sodium oxide $\left(\mathrm{Na}_{2} \mathrm{O}_{3}\right)$. The amount of these elements varied from 0.010 to $0.020 \%$ by volume and little representation did not affect negatively the results of biocompatibility.

The direct cytotoxic evaluation simulated the direct contact between the abutment's Y-TZP and oral gingival fibroblasts at 24, 48 and $72 \mathrm{hrs}$. The EP biological behavior was similar to the two other commercially available materials, regardless of the periods of evaluation, suggesting that the cellular viability is not affected by this material (Figure 2). In a previous study, $\mathrm{ZrO}_{2}$ abutments showed higher amounts of collagen deposition as well as larger fractions of fibroblasts and leukocytes adhered to the surface than the connective tissue interface of the $\mathrm{Ti}$ abutments, suggesting that the soft tissue healing to zirconia's abutments is better than alloy abutments [10]. When comparing the zirconia to the feldspatic porcelain, the adhesion capacity and the cellular growth rate of the fibroblasts were strongly increased [7].

The indirect cytotoxic evaluation was done to simulate the indirect contact of the gingival fibroblasts from the surrounding gingival tissues with the zirconia's abutment at 24, 48 and $72 \mathrm{hrs}$. After $72 \mathrm{hrs}$, there was a proliferation of cultured HGFs compared to $48 \mathrm{hrs}$ in the EP and ST disc groups (Figure 3). It seems that the direct contact of the cells with the discs had no impact in the HGF metabolism, a later exposition of the cells that are far from the EP and ST discs (indirect contact) could benefit the proliferation rate by increasing the cell viability. EP has $\mathrm{TiO}_{2}$ and $\mathrm{Cl}$. These components are sediments not possible to separate during zirconium dioxide extraction, however, Zirconia containing $\mathrm{TiO}_{2}$ in larger percentages improved fibroblast cells adhesion on their surfaces [18].

Chemically, the phase transformation caused changes in the $\mathrm{Zr}-\mathrm{O}$ bonds detected by the Raman spectroscopy $[19,20]$. Raman scattering is best suited for systems in which the electron cloud may be deformed [21]. More specifically, during the Raman measurements, when a laser light strikes a sample, it acts by deforming the electron cloud, which will cause scattering and elements detection [21].

The bands are a set of wave numbers which contain a main wave number related to the peak of the band. The current study identified five wave numbers of the peaks $\left(\sim 260,320,464,642\right.$ and $\left.147 \mathrm{~cm}^{-1}\right)$ similar to the frequencies of vibration corresponded to the six Raman active bands of the tetragonal Y-TZP [15] (Figure 4). According to some studies it is possible to identify the three main phases (monoclinic, tetragonal and cubic) because they exhibits changes in the zirconium oxide bond angles and lengths, indicating the phase transformation $[15,19,22]$. The main broad bands shown in our study were at $\sim 260$, 464 , and $642 \mathrm{~cm}^{-1}$ (Figure 4). They are due to tetragonal or cubic phases [15]. Different chemical stabilizers and crystal size probably caused few spectral variations at the tetragonal/cubic phases of this study ( 260, 464, and $642 \mathrm{~cm}^{-1}$ ) [22,23] (Figure 4). The chemical stabilizers are almost the same for the three studied groups, except for some above described tracer elements for the EP (titanium dioxide and Clorium) and for the ST (aluminium trioxide). The EP Y-TZP was pressed by isostatic pressure, which is a powder compression inside a flexible mold under a pressurized fluid action. This procedure ensures a homogenous load distribution under the mold surface. This hindrance that the pressure applied is uniformly distributed to all the regions, causing density gradients upon the formed Y-TZP blocks [24]. In contrast, the uniaxial pressure causes the friction among the powder particles and also the friction between them and the mold surfaces [24,25].

These differences mainly compared to the ST and ZK, can be maintained for the EP, since the pressing of the chemical components ensures the mechanical stability, avoiding any premature phase transformations identified by the bands (Figure 4). The higher the quality in the pressing step, the lesser the intrinsic defects are produced, which can influence the grain growth and density at the grain boundaries during the elements compaction. Commercially Y-TZPs phase transformations were identified by Raman after fatigue, which is expected for that moment, not before clinical use [20]. Therefore, we suppose that the Y-TZPs tetragonal phase shown in the current study can indicate that the intrinsic stability can preserve the fibroblast cells viability in contact with them. 
Citation: Borges AFS, Morandini AC, Ramos CM, de Oliveira MBS, Tabata A, et al. (2013) Biological and Structural Characterization of Y-TZP for Implant Abutments. J Tissue Sci Eng 5: 132. doi:10.4172/2157-7552.1000132

\section{Conclusion}

Within the limitation of this study, all the Y-TZP showed the biocompatibility and crystalline structures expected for Y-ZTP and recommended for use as implants abutments.

\section{Acknowledgment}

There are no conflicts of interest associated with this study. This study was in part supported by the São Paulo State Research Foundation (grant 2010/01230-1).

\section{References}

1. Andersson B, Glauser R, Maglione M, Taylor A (2003) Ceramic implan abutments for short-span FPDs: a prospective 5-year multicenter study. Int J Prosthodont 16: 640-646.

2. Piconi C, Maccauro G (1999) Zirconia as a ceramic biomaterial. Biomaterials 20: 1-25.

3. Kisi EH, Howard CJ (1998) Crystal structures of zirconia phases and their interrelation. Key Eng Mater 153: 1-36.

4. Manicone PF, Rossi lommetti P, Raffaelli L, Paolantonio M, Rossi G, et al (2007) Biological considerations on the use of zirconia for dental devices. Int $J$ ImmunopatholPharmacol 20: 9-12.

5. Baldassarri M, Hjerppe J, Romeo D, Fickl S, Thompson VP, et al. (2012) Marginal accuracy of three implant-ceramic abutment configurations. Int J Oral Maxillofac Implants 27: 537-543.

6. Park JI, Lee Y, Lee JH, Kim YL, Bae JM, et al. (2013) Comparison of fracture resistance and fit accuracy of customized zirconia abutments with prefabricated zirconia abutments in internal hexagonal implants. Clin Implant Dent Relat Res 15: $769-778$

7. Raffaelli L, Rossi lommetti P, Piccioni E, Toesca A, Serini S, et al. (2008) Growth, viability, adhesion potential, and fibronectin expression in fibroblasts cultured on zirconia or feldspatic ceramics in vitro. J Biomed Mater Res A 86 959-968.

8. Mustafa K, Wennerberg A, Arvidson K, Messelt EB, Haag P, et al. (2008) Influence of modifying and veneering the surface of ceramic abutments on cellular attachment and proliferation. Clin Oral Implants Res 19: 1178-1187.

9. Welander M, Abrahamsson I, Berglundh T (2008) The mucosal barrier at implant abutments of different materials. Clin Oral Implants Res 19: 635-641.

10. Pae A, Lee H, Kim HS, Kwon YD, Woo YH (2009) Attachment and growth behaviour of human gingival fibroblasts on titanium and zirconia ceramic surfaces. Biomed Mater 4: 025005.

11. Schwartz-Filho HO, Morandini AC, Ramos-Junior ES, Jimbo R, Santos CF, et al. (2012) Titanium surfaces with nanotopography modulate cytokine production in cultured human gingival fibroblasts. J Biomed Mater Res A 100: 2629-2636.
12. Rimondini L, Cerroni L, Carrassi A, Torricelli P (2002) Bacterial colonization of zirconia ceramic surfaces: an in vitro and in vivo study. Int $\mathrm{J}$ Oral Maxillofac Implants 17: 793-798.

13. Degidi M, Artese L, Scarano A, Perrotti V, Gehrke P, et al. (2006). Inflammatory infiltrate, microvessel density, nitric oxide synthase expression, vascularendothelial growth factor expression, and proliferativeactivity in peri-implant soft tissues around titanium andzirconium oxide healing caps. J Periodontol 77: 73-80.

14. Pittayachawan P, McDonald A, Young A, Knowles JC (2009) Flexural strength, fatigue life, and stress-induced phase transformation study of Y-TZP dental ceramic. J Biomed Mater Res B ApplBiomater 88: 366-377

15. Durand JC, Jacquot B, Salehi H, Fages M, Margerit J, et al. (2012) Confoca Raman microscopic analysis of thezirconia/feldspathic ceramic interface. Dent Mater 28: 661-671.

16. Borba M, de Araújo MD, de Lima E, Yoshimura HN, Cesar PF, et al. (2011) Flexural strength and failure modes of layered ceramic structures. Dent Mate 27: $1259-1266$

17. Morandini ACF, Sipert CR, Gasparoto TH, Greghi SL, Passanezi E, et al. (2010) Differential Production of Macrophage Inflammatory Protein-1a, StromalDerived Factor-1, and IL-6 by Human Cultured Periodontal Ligament and Gingival Fibroblasts Challenged With Lipopolysaccharide From P. gingivalis. J Periodontol 81: 310-317.

18. Marchi J, Ussui V, Delfino CS, Bressiani AH, Marques MM (2010) Analysis in vitro of the cytotoxicity of potential implant materials. I: Zirconia-titania sintered ceramics. J Biomed Mater Res B ApplBiomater 94: 305-311.

19. Ishigame M, Sakurai T (1977) Temperature dependence of the Raman spectra of ZrO2. J Am Ceram Soc 60: 367-369.

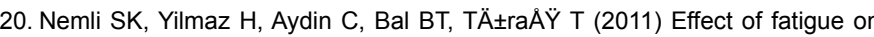
fracture toughness and phase transformation of $\mathrm{Y}$-TZP ceramics by $\mathrm{X}$-ray diffraction and Raman spectroscopy. J Biomed Mater Res B ApplBiomater .

21. Bouvier P, Lucazeau G (2000) Raman spectra and vibrational analysis of nanometric tetragonal zirconia under high pressure. J Phys Chem Solids 61 569-578.

22. Casellas D, Cumbrera FL, Sanchez-Bajo F, Forsling W, Llanes L, et al. (2001) On the transformation toughening of $\mathrm{Y}$-ZrO2 ceramics with mixed Y-TZP/PSZ microstuctures. J Eur Ceram Soc 21:765-777.

23. Djurado E, Bouvier P, Lucazeau G (2000) Crystallite size effect on the tetragonal-monoclinic transition of undopednanocrystalline zirconia studied by XRD and Raman Spectrometry. J Solid State Chem 149: 399-407.

24. Reed JS (1995) Principles of Ceramic Processing. Wiley Sons 658.

25. German RM (1996) Sintering Theory and Practice.Wiley Sons 550. 